\title{
Importance of access to research information among individuals with spinal cord injury: results of an evidenced-based questionnaire
}

\author{
L Edwards $^{1,2}$, A Krassioukov ${ }^{1,2,3,4,5}$ and MG Fehlings*,1,2,3,4 \\ ${ }^{1}$ Toronto Western Research Institute, Toronto Western Hospital, University Health Network, Toronto, Canada; \\ ${ }^{2}$ Institute of Medical Science, University of Toronto, Toronto, Canada; ${ }^{3}$ Department of Surgery, Division of \\ Neurosurgery, University of Toronto, Toronto, Canada; ${ }^{4}$ Spinal Program, Krembil Neuroscience Center, Toronto \\ Western Hospital, University Health Network, Toronto, Canada; ${ }^{5}$ Department of Physical Medicine and \\ Rehabilitation, University of Western Ontario, London, Ontario, Canada
}

\begin{abstract}
Objective: To assess the interests and accessibility of patients with a spinal cord injury (SCI) to information in different areas of SCI.

Setting: Spinal Program, Toronto Western Hospital, University Health Network.

Methods: An interest assessment survey and the SF-36 (short form-36) questionnaire were mailed to SCI patients living in the community. The interest assessment examined patients' interest in information in many areas related to SCI, their current knowledge in these areas and the accessibility of different information formats.

Results: Fourteen patients $(45 \%)$ completed the questionnaires. Regardless of physical or mental health status, all patients expressed a high level of interest in SCI research and clinical trials. An Internet website proved to be the most preferred, accessible and comfortable information format for these patients. Patients expressed a lower interest in support groups and organizations. Results from the SF-36 showed poor social functioning was related to interest in support groups, and poor general health perception was related to interest in occupational and physical therapy.

Conclusion: The majority of SCI patients have a high interest in accessing SCI research information. The Internet is a favorable, comfortable and accessible tool for providing this information and will benefit all SCI patients. These results suggest that a significant number of patients with SCI would benefit from an accessible Internet-based information database that is relevant to the SCI patients population.
\end{abstract}

Spinal Cord (2002) 40, 529-535. doi:10.1038/sj.sc.3101364

Keywords: spinal cord injury; quality of life; information accessibility

\section{Introduction}

One of the largest problems facing patients with spinal cord injuries (SCI) is coping with the changes in their quality of life associated with the injury. There is a tremendous amount of education these patients must receive in order to try to adapt to their environment and cope with their situation. This primarily comes from their contact with nurses, therapists, and counselors at a variety of tertiary care centers. Many studies have shown that education significantly correlates with a patient's life satisfaction, productivity, and sense of empowerment and self-reliance. ${ }^{1-3}$

A study of the role of nurses as teachers showed that patients' involvement in their education regarding

*Correspondence: M Fehlings, Toronto Western Hospital, 399 Bathurst St. 4W-427 Toronto, ON, M5T 2S8, Canada
SCI played an important role in the goal of successful rehabilitation. ${ }^{4}$ The authors stress the importance of the patient's involvement to direct and plan his or her own care. Stewart and Bhagwanjee (1999) conducted a study that found patient participation in research, control over resources, and stressing the role of the health professional in creating opportunities for patients, are key elements in facilitating a sense of empowerment and self-reliance for patients. ${ }^{3}$ Richards et al (1999) found that access to the external environment independent of the person's physical disability (described as an 'outside the person' factor) is important in predicting satisfaction in life for individuals with SCI. ${ }^{5}$

Based on these findings, we predict that access to information in areas of SCI research and technolology 
may give patients a better sense of empowerment, independence and self-reliance to help cope with their injuries. The goal of this study was to conduct an interest assessment of patients with SCI. This study attempted to address four main questions. What areas of SCI are of the most interest to patients? What is their current knowledge in areas of SCI? How often would they access information regarding SCI? What format would they prefer to access their information regarding SCI?

To evaluate these questions an interest assessment survey (IAS) was constructed that was readable, easy to complete and sufficiently covered potential areas of interest for these patients. The survey was completed along with a general health perception survey, the Medical Outcomes Study Short Form 36 (SF-36), to draw correlations between patients' interest in areas of SCI and their health status.

\section{Methods}

The interest assessment survey and the SF-36 questionnaire, along with a cover letter, were mailed out to 31 patients from The Spinal Program at the Toronto Western Hospital, University Health Network, with a stamped and self-addressed return envelope. The survey was also available on the Internet by e-mail request. In order to increase the response rate, a telephone interview with some of the individuals was conducted.

\section{The interest assessment survey (IAS)}

The IAS was developed with the input of many members of the Spinal Program, including physicians, a clinical trials nurse, acute care nurses, occupational and physical therapists and the Quality Team, a team designed to specifically address quality of life issues for these patients. The IAS consisted of a series of short answers, multiple choice questions, and rating scales to evaluate four main issues: (1) patient demographics; (2) interest in areas of SCI; (3) accessibility to different information formats; (4) patient's current knowledge in areas of SCI. Table 1 outlines the general properties and structure of the IAS.

The patient demographics consisted of age, number of months/years since the SCI, and the level of SCI. No data were collected regarding gender or severity of the injury. The patients' general interest in accessing

Table 1 General properties of the interest assessment survey in the areas of spinal cord injury

\begin{tabular}{llc}
\hline Area & Question type & $\begin{array}{c}\text { Number of } \\
\text { questions }\end{array}$ \\
\hline Demographics & Short answer & 3 \\
Interest & Multiple choice & 1 \\
Accessibility & Rating scales & 6 \\
Current knowledge & Multiple choice & 5 \\
\hline
\end{tabular}

information in the SCI field was measured, as well as the frequency with which they felt they would access the information. To assess accessibility to different formats of information, multiple choice questions regarding where they currently receive their information, what format they would prefer the information (website, newsletter, seminar series, etc), and to what extent do they have access to each of these formats were used.

The patients' level of interest in the following areas of SCI was investigated: (1) advances in research; (2) current clinical trials; (3) occupational and physical therapy; (4) support groups and (5) national and international SCI organizations. The questions regarding patients' current knowledge in areas of SCI covered research, support groups and national/international organizations. Current knowledge of participants in the following topics was also assessed: nerve transplants, nerve regeneration, drug therapies, drug treatment to reduce cell death, programmed cell death, Canadian Paraplegic Association, Rick Hansen Foundation, Think First Campaign and the Canadian Spinal Research Organization.

\section{SF-36 (short form-36)}

The inclusion of the Medical Outcomes Study Short Form 36 (SF-36) with the IAS served two main purposes. First, the results of SF-36 could be compared to the previously published data from patients with SCI in order to compare our sample population to that of the general SCI population or other patient groups. Second, the inclusion of the SF-36 was done to draw correlations between patients' interests in areas of SCI and their general health status. The SF-36 is a general measure that provides a profile of health status, providing scores on eight dimensions of functioning and well-being of the individual (Table 2). Scores for each question of SF-36 were coded and transformed to a scale of 0 (poorest health) to 100 (best health). The results of the SF-36 can be summarized into two summary measures: the Physical Component Summary (PCS) and the Mental Component Summary (MCS). ${ }^{6}$ The average score of the Physical Functioning, Physical Role Limitations, and Pain Perception scales

Table 2 Outline of the components of the medical outcomes study short form 36 (SF-36)

\begin{tabular}{llc}
\hline Area & Dimension & $\begin{array}{c}\text { Number of } \\
\text { questions }\end{array}$ \\
\hline Functional status & Physical functioning & 10 \\
& Social functioning & 2 \\
& Physical role limitation & 4 \\
Well being & Emotional role limitation & 3 \\
Overall health & Pain & 9 \\
evaluation & Cheneral health perception & 2 \\
& & 5 \\
\hline
\end{tabular}


calculate a reliable measure of physical health (PCS). A reliable measure of mental health (MCS) is calculated from the average of the Social Functioning, Emotional Role Limitation, and Mental Health and Vitality scales. In this study we used both the individual dimension scores and the summary scores for analysis. The SF-36 was previously developed by the RAND Corporation's Health Insurance Experiment in the United States and the purpose and methods of the RAND study have been summarized elsewhere. ${ }^{7}$

\section{Statistical analysis}

Descriptive statistics were used for the evaluation of demographic data. Evaluation of the interest in areas of SCI and current knowledge in areas of SCI was analyzed during the Kruskal-Wallis one-way analysis of variance on ranks due to the non-normal distribution of the data. Post-hoc multiple comparisons on the differences of ranks were also performed. Analysis of categorical data regarding frequency of access to information, information formats and comfort with the Internet was done using chi-square test. Correlations between measures in the IAS and the SF-36 summary scores were done using a Pearson Product Moment Correlation. Statistical significance was considered at $P<0.05$.

\section{Results}

\section{Demographic data}

Of the original 31 mailed surveys, 14 responses were received with a response rate of $45 \%$. The average age of participants was $38.0 \pm 3.91$ years, ranging from 19 to 67 years, with median at 31 years. The average time post injury was $31.6 \pm 8.7$ months and ranged from 5 months to 8 years, with a median of 19 months. All participants had cervical SCI involving C6 or higher.

\section{Interest assessment}

The results of the IAS on area of interest to SCI patients is shown in Table 3. Overall there was a very high general interest in research of SCI among participants. When asked about specific areas of the SCI field, patients rated information in the areas of research and clinical trials as the ones of highest interest. Patients had a slightly lower interest in physical and occupational therapy and the lowest interest in support groups and organizations. Patients rated their interest in research and clinical trials significantly higher than their interest in support groups and organizations $(\mathrm{H}=41.91, P<0.001)$.

\section{Assessment of accessibility}

The results of the assessment of accessibility to different information formats is shown in Tables 4 and 5. Over two-thirds of the respondents reported using the Internet as one of their current sources of information. A significant proportion $(78 \%)$ of the participants reported the Internet as their preferred format to access information $\left(\chi^{2}=13.85, P<0.005\right)$. Fewer respondents preferred a newsletter format and none chose a seminar series. Assessment of accessibility to the Internet revealed that all respondents had at least some access to the Internet, and a significant majority $(71.4 \%)$ reported having access to it all the time $\left(\chi^{2}=24.57, P<0.005\right)$. The majority of participants $(85.7 \%)$ reported being very comfortable with the Internet, and none of the respondents reported

Table 3 Assessment of interest in areas of spinal cord injury

\begin{tabular}{lccc}
\hline Areas of & Median & \multicolumn{2}{c}{ Quartile: } \\
interest & score & $25 \%$ & $75 \%$ \\
\hline General interest & 4.5 & 4.0 & 5.0 \\
Scientific research & $5.0^{\mathrm{a}}$ & 4.0 & 5.0 \\
Clinical trials & $5.0^{\mathrm{a}}$ & 4.0 & 5.0 \\
Physical and occupational & 4.0 & 3.0 & 4.0 \\
$\quad$ therapy & & & \\
Support groups & $3.0^{\mathrm{b}}$ & 2.0 & 3.0 \\
Organizations & $3.0^{\mathrm{b}}$ & 2.0 & 4.0 \\
\hline
\end{tabular}

Different letters represent significant differences in interest in the level of interest patients reported in different areas of SCI $(P<0.05)$

Table 4 Assessment of frequency and accessibility to different information formats

\begin{tabular}{|c|c|c|c|c|c|}
\hline \multicolumn{2}{|c|}{$\begin{array}{l}\text { Frequency of access } \\
\text { to information }\end{array}$} & \multicolumn{2}{|l|}{$\begin{array}{l}\text { Current } \\
\text { information }\end{array}$} & \multicolumn{2}{|l|}{$\begin{array}{l}\text { Preferred } \\
\text { format }\end{array}$} \\
\hline Frequency & $\%$ & Source & $\% * *$ & Source & $\% *$ \\
\hline Weekly & 42.8 & Internet & 64.3 & Website & 78.6 \\
\hline Monthly & 28.6 & Physician & 35.7 & Newsletter & 21.4 \\
\hline $2-4 /$ year & 28.6 & Newsletter & 35.7 & Seminars & 0 \\
\hline $1 /$ year & 0 & Newspapers/Magazines & 35.7 & & \\
\hline \multirow[t]{2}{*}{ Never } & 0 & Support groups & 21.4 & & \\
\hline & & Organizations & 21.4 & & \\
\hline
\end{tabular}

*For each question, the percentage represents the per cent of respondents choosing each option. **For the current information, respondents were not limited to just one choice 
Table 5 Assessment of accessibility to and comfort with different information formats

\begin{tabular}{llllll}
\hline Internet accessibility & & & \multicolumn{2}{l}{ Seminar accessibility } \\
\hline Internet access & $\% *$ & Comfort with Internet & $\%$ & Seminar & $\%$ \\
\hline Always & 71.4 & Very & 85.7 & Monthly & 14.3 \\
Often & 14.3 & Somewhat & 14.3 & $2-4 /$ year & 35.7 \\
Sometimes & 14.3 & Not at all & 0 & Once $/$ year & 35.7 \\
Infrequent & 0 & & & Never & 14.3 \\
Never & 0 & & & \\
\hline
\end{tabular}

*For each question, the percentage represents the percent of respondents choosing each option

having no experience with the Internet $\left(\chi^{2}=17.7\right.$, $P<0.05)$. A significant number of respondents reported they would like to access information regarding SCI weekly $\left(\chi^{2}=10.29, P<0.005\right)$, but when asked how frequently they would attend an information seminar the frequency dropped to $1-4$ times a year. This, along with the low level of interest in seminar as an information format, suggest that seminars are not a good choice for disseminating information to the SCI population.

\section{Assessment of current knowledge}

The results of the assessment of current knowledge in areas of SCI are shown in Table 6. Respondents had very little knowledge regarding current topics of SCI research, such as nerve transplantation, drug treatments, reduction in cell death and apoptosis. The knowledge of the Canadian Paraplegia Association (CPA) was the highest of all topics sampled, and participants rated their knowledge of the CPA significantly higher than some of the areas of SCI research (cell death and apoptosis) as well as the Think First SCI prevention campaign $(\mathrm{H}=30.91, P<0.001)$. Knowledge of other organizations relevant to the SCI population (Rick Hansen Foundation and CRSO) was much less than the CPA and reflected that of the topics in SCI research.

\section{Medical outcomes study short form 36}

Overall respondents scored very low on the Physical Functioning, Physical Role Limitations, and the Physical Component Summary (PCS) measures (Table 7). The remaining measures range from 50.9 for Social Functioning to 66.7 for Emotional Role Limitations. There was a weakly positive correlation between the time after injury and the emotional health of the patient $(r=0.56, P<0.05)$. Therefore, in general a patient's emotional and mental health improved with time after injury. Patients' age was negatively correlated with their social functioning, although this did not reach significance $(r=-0.43, P=0.12)$. Therefore, in general a patient's emotional and mental health improved with time after injury.

Regardless of health status measures, all patients reported the highest level of interest in SCI research
Table 6 Assessment of current knowledge in areas of spinal cord injury

\begin{tabular}{lccc}
\hline \multirow{2}{*}{$\begin{array}{l}\text { Areas of } \\
\text { interest }\end{array}$} & $\begin{array}{c}\text { Median } \\
\text { score }\end{array}$ & \multicolumn{2}{c}{ Quartile: } \\
\hline Transplantation & 2.0 & 1.0 & $75 \%$ \\
Regeneration & 3.0 & 2.0 & 3.0 \\
Drug treatments & 2.0 & 1.0 & 3.0 \\
Reduction in cell death & $2.0^{\mathrm{a}}$ & 1.0 & 2.0 \\
Apoptosis & $1.0^{\mathrm{a}}$ & 1.0 & 2.0 \\
Canadian Paraplegic & $4.0^{\mathrm{b}}$ & 3.0 & 5.0 \\
$\quad$ Association (CPA) & & & \\
Rick Hansen Foundation & 2.0 & 1.0 & 3.0 \\
Think First SCI Prevention & $1.0^{\mathrm{a}}$ & 1.0 & 1.0 \\
Canadian Spinal Research & 1.0 & 1.0 & 3.0 \\
$\quad$ Organization (CRSO) & & & \\
\hline
\end{tabular}

Different letters represent significant differences in knowledge reported by patients in different areas of SCI $(P<0.05)$

and clinical trials (Table 3). Due to the skewed distribution of the scores for the overall interest in SCI research and clinical trials it was not possible to conduct a correlation between the patient's interest in these areas and their health status.

Correlation between time post injury, age and SF-36 with the interest assessment survey

Neither time after injury nor age were correlated with interest in therapy, support groups or organizations. Interest in support groups was negatively correlated with social functioning $(r=-0.67, P=0.01)$ and interest in therapy was negatively correlated with the patient's general health perception $(r=-0.60$, $P=0.02)$. Mental health and vitality scores were not significantly correlated with interest in organizations $(r=0.40, P=0.16)$.

Correlation between physical and mental summary scores of SF-36 with interest assessment survey, time postinjury and age

Correlation of the physical (PCS) and mental (MCS) health component summary measures with patient's interest in support groups, organizations and time post injury were investigated. These results are shown in Table 8. Patients' MCS and PCS scores were highly 
Table 7 Scores for the SF-36 scales for 14 spinal cord injured patients

\begin{tabular}{|c|c|c|c|c|c|}
\hline Dimension & & $\begin{array}{l}\text { Mean } \\
\text { score }\end{array}$ & s.e.m.* & $\begin{array}{l}\text { Minimum } \\
(\mathrm{n} / 14)^{* *}\end{array}$ & $\underset{(\mathrm{n} / 14)^{* *}}{\operatorname{Maximum}}$ \\
\hline Physical functioning & 10 & & 6.37 & $0(5)$ & $70(1)$ \\
\hline Role limits-physical & 4 & & 9.87 & $0(10)$ & $100(1)$ \\
\hline Social functioning & 2 & & 8.34 & $12.5(3)$ & $100(2)$ \\
\hline Role limits-emotional & 3 & & 12.6 & $0(4)$ & $100(8)$ \\
\hline Mental health \& vitality & 9 & & 4.49 & $126.6(1)$ & $86.6(1)$ \\
\hline Pain & 2 & & 5.93 & 22.2 & $99.9(2)$ \\
\hline General health & 5 & & 5.17 & $20(1)$ & $90(1)$ \\
\hline Health change & 1 & & 8.76 & $0(2)$ & $100(2)$ \\
\hline PCS & 16 & & 3.79 & $14.8(1)$ & $60.5(1)$ \\
\hline MCS & 14 & & 6.43 & $13.0(1)$ & $95.5(1)$ \\
\hline
\end{tabular}

*Standard Error of the Mean. **Number of respondents reporting the score out of the 14 total respondents

Table 8 Correlation between PCS and MCS scores and interest in areas of the spinal cord injury

\begin{tabular}{|c|c|c|c|c|c|}
\hline & $M C S$ & Time & $\begin{array}{c}O T \text { and } \\
P T\end{array}$ & $\begin{array}{l}\text { Support } \\
\text { groups }\end{array}$ & $\begin{array}{l}\text { Organi- } \\
\text { zations }\end{array}$ \\
\hline PCS & 0.62 & 0.43 & -0.45 & -0.28 & -0.06 \\
\hline & $0.02 * *$ & $0.12^{*}$ & $0.10^{*}$ & 0.34 & 0.83 \\
\hline MCS & & $\begin{array}{l}0.47 \\
0.08 *\end{array}$ & $\begin{array}{r}-0.04 \\
0.90\end{array}$ & $\begin{array}{r}-0.12 \\
0.67\end{array}$ & $\begin{array}{l}0.12 \\
0.68\end{array}$ \\
\hline
\end{tabular}

The top numbers represent the Pearson correlation and the probability value of the correlation in italics. $* * P<0.05$ shows statistical significance. *Probabilities less than 0.15 are reported as a trend to significance of the correlation. $\mathrm{MCS}=$ Mental Component Summary; OT = Occupational Therapy; $\mathrm{PCS}=$ Physical Component Summary; $\mathrm{PT}=$ Physical Therapy

correlated with each other. In general, a patient's reported physical and mental health improves over time after injury, although this did not reach significance. Neither the patient's physical nor mental health status correlated with their interest in support groups or organizations. However, although it did not reach significance, physical health (PCS) was negatively correlated with interest in therapy $(r=0.45 ; P-0,10)$ meaning that those with poor physical health are very interested in physical and occupational therapy.

\section{Discussion}

\section{Demographic data}

The response rate for self-administrated questionnaires varies from 24 to $83 \%{ }^{8-10}$ The response rate in our study $(45 \%)$ was comparable to other self-reported surveys of individuals with SCI. ${ }^{11,12}$ All participants in our study had a spinal cord injury involving the cervical spine, which is representative of two-thirds of the SCI populations. ${ }^{13,14}$ The average age of the respondents $(31 \pm 3.9)$ was also representative of the SCI populations as a whole. ${ }^{13}$
Interest assessment

The results of the interest assessment show a very high level of interest in accessing information about SCI. The areas of most interest to patients are those related to SCI research and clinical trials. Patients expressed a lesser degree of interest in support groups and organizations. When questioned about their current knowledge in specific items related to each of these general topics patients revealed a better knowledge of support groups and organizations while having less knowledge about areas of SCI research. These findings probably suggest that patients have already utilized the information from support groups and organizations prior to the survey, which may in part explain their lower interest in these areas. Although the survey questioned knowledge regarding support groups and organizations, it did not directly inquire about previous use of these services. Patients reported limited knowledge of SCI research areas, which supports their high level of interest in this area. These results suggest that dissemination of information focused on SCI research would be of most interest to the SCI patient population.

\section{Accessibility to information}

This study addressed the issue of access to information for SCI patients by questioning the frequency with which they would access information and what format this information should be disseminated. A significant number of respondents $(78.6 \%)$ preferred an Internet website as a format for accessing information. The majority of this patient population reported the Internet as currently their main source of information, even above that of their physician, support groups and organizations. All respondents reported at least some access to the Internet and the far majority of respondents $(71.4 \%)$ have access to the Internet at all times. Finally, as the Internet is a relatively new information source when compared to the other sources asked about in this study, we questioned patients' comfort in utilizing the Internet as an information source. Almost all respondents 
$(85.7 \%)$ reported being very comfortable in using the Internet.

\section{SF-36 as a reliable and accurate measure of perceived} health status

The SF-36 has been shown to exhibit both test-retest reliability and content validity proving itself to be both an accurate measure of perceived health status and a valid one as well. . $^{9,10,15,16}$ This measure has also been used in many different populations, including healthy individuals, ${ }^{17}$ Parkinson's patients, ${ }^{18}$ AIDS patients ${ }^{19}$ and patients with traumatic brain injury. ${ }^{8}$ Low scores on the Physical Functioning, Physical Role Limitations, and the Physical Component Summary measures in our study were not surprising considering the level of the spinal cord injury of these patients. Although these scores were noticeably lower than those measured for healthy individuals, ${ }^{17}$ measures of Physical Component Summary (PCS) and Mental Component Summary (MCS) in our study were similar to those reported for patients with traumatic brain injury. ${ }^{8}$ Overall, this indicates that our SCI patient population is an adequate representative sample for information collected from the SF-36. From this it can be inferred that the information collected from the interest assessment is also representative of the SCI patient population in general.

\section{SF-36 as a predictor of interest in SCI research}

All patients questioned showed a high level of interest in SCI research and clinical trials, regardless of their scores on the SF-36. Therefore, providing information about SCI research and clinical trials would benefit all SCI patients and would be accessed by all patients.

\section{SF-36 as a predictor of interest in support groups and organizations}

Results from the SF-36 questionnaire showed that patients with better mental health and vitality scores tended to be interested in national and international organizations, although this correlation did not reach significance. However, the Mental Component Summary (MCS) score in our study did not support these findings. The MCS is a combination of the social functioning, mental health and vitality and emotional role limitations dimensions of the SF-36. In fact, the MCS scores did not correlate with patients' interest in either support groups or organizations. Studies have shown that the MCS is a more complete evaluation of mental status. ${ }^{6,8}$ Based on this evidence, our results show that interest in support groups and organizations is not related to a patient's mental health. The results of this study did show that patients with poor social functioning showed a high interest in support groups. These results suggest that evaluation of social functioning may be useful in identifying patients who have interest in and will benefit from SCI support groups.
SF-36 as a predictor of interest in occupational and physical therapy

Patients with poor physical health as measured by the PCS, or a poor general health perception are more interested in occupational and physical therapy. These results may be expected, and provide support for the validity of the SF-36 measures shown in other studies. ${ }^{9,10,15-20}$

\section{Conclusions}

The interest assessment showed that SCI patients in our study have a high interest in SCI research and clinical trials and a lower interest in support groups and organizations. The Internet is the most preferred source of information, patients have a high degree of access to the Internet and are very comfortable with this information format. The results of this study have prompted the Spinal Program to develop a website, which will provide patients with information about many areas of the SCI field.

\section{Acknowledgements}

L Edwards is supported by a Medical Research Council of Canada MD/PhD Studentship. A Krassioukov is supported by the Christopher Reeve Paralysis Foundation and the Cervical Spinal Research Society. MG Fehlings is supported by a Career Investigator Award from the Ontario Ministry of Health and holds the Krembil Chair in Neural Repair and Regeneration. The technical assistance of Karen Scales is gratefully acknowledged. The authors thank Linda Rickards RN and Sandy Robinson $\mathrm{RN}$ for advice and assistance during the project.

\section{References}

1 Vogel LC, Klaas SJ, Lubicky JP, Anderson CJ. Longterm outcomes and life satisfaction of adults who had pediatric spinal cord injuries. Arch Phys Med Rehabil 1998; 79: $1496-1503$.

2 Noreau L et al. Productivity outcomes of individuals with spinal cord injury. Spinal Cord 1999; 37: 730-736.

3 Stewart R, Bhagwanjee A. Promoting group empowerment and self-reliance through participatory research: a case study of people with physical disability. Disabil Rehabil 1999; 21: 338 - 345.

4 Spoltore TA, O'Brien AM. Rehabilitation of the spinal cord injured patient. Orthop Nurs 1995; 14: 7-14; quiz $15-16$.

5 Richards JS et al. Access to the environment and life satisfaction after spinal cord injury. Arch Phys Med Rehabil 1999; 80: $1501-1506$

6 Ware Jr JE et al. Comparison of methods for the scoring and statistical analysis of SF-36 health profile and summary measures: summary of results from the Medical Outcomes Study. Med Care 1995; 33 (Suppl 4): AS264AS279.

7 Stewart A, Ware J. Measuring functioning and well-being: The medical outcomes study approach. London: Duke University Press 1992, 45-46 pp. 
8 Corrigan JD, Smith-Knapp K, Granger CV. Outcomes in the first 5 years after traumatic brain injury. Arch Phys Med Rehabil 1998; 79: 298-305.

9 Brazier JE et al. Validating the SF-36 health survey questionnaire: new outcome measure for primary care [see comments]. BMJ 1992; 305: $160-164$.

10 Stansfeld SA, Roberts R, Foot SP. Assessing the validity of the SF-36 General Health Survey. Qual Life Res 1997; 6: $217-224$

11 Widerstrom-Noga EG et al. Perceived difficulty in dealing with consequences of spinal cord injury. Arch Phys Med Rehabil 1999; 80: 580-586.

12 Widerstrom-Noga EG, Felipe-Cuervo E, Yezierski RP. Relationships among clinical characteristics of chronic pain after spinal cord injury. Arch Phys Med Rehabil 2001; 80: $1191-1197$.

13 Sekhon LH, Fehlings MG. Epidemiology, demographics, and pathophysiology of acute spinal cord injury. Spine 2001; 26 (Suppl 24): S2-S12.

14 Tator $\mathrm{CH}$, Fehlings MG, Thorpe K, Taylor W. Current use and timing of spinal surgery for management of acute spinal surgery for management of acute spinal cord injury in North America: results of a retrospective multicenter study. J Neurosurg 1999; 91 (Suppl 1): $12-$ 18.
15 Jenkinson $\mathrm{C}$ et al. Evaluation of index and profile measures of health status in a randomized controlled trial. Comparison of the Medical Outcomes Study 36Item Short Form Health Survey, EuroQol, and disease specific measures. Med Care 1997; 35: 1109-1118.

16 Essink-Bot ML, Krabbe PF, Bonsel GJ, Aaronson NK. An empirical comparison of four generic health status measures. The Nottingham Health Profile, the Medical Outcomes Study 36-item Short-Form Health Survey, the COOP/WONCA charts, and the EuroQol instrument. Med Care 1997; 35: 522-537.

17 Shmueli A. The SF-36 profile and health-related quality of life: an interpretative analysis. Qual Life Res 1998; 7: $187-195$.

18 Jenkinson C, Fitzpatrick R, Peto V. Health-related quality-of-life measurement in patients with Parkinson's disease. Pharmacoeconomics 1999; 15: 157-165.

19 Anderson JP, Kaplan RM, Coons SJ, Schneiderman LJ. Comparison of the Quality of Well-being Scale and the SF-36 results among two samples of ill adults: AIDS and other illnesses. J Clin Epidemiol 1998; 51: 755-762.

20 Vickrey BG et al. Comparison of a generic to diseasetargeted health-related quality-of-life measures for multiple sclerosis. J Clin Epidemiol 1997; 50: 557-569. 